NOTE

Daniel Keunecke $\cdot$ Michaela Eder · Ingo Burgert

Peter Niemz

\title{
Micromechanical properties of common yew (Taxus baccata) and Norway spruce (Picea abies) transition wood fibers subjected to longitudinal tension
}

Received: December 17, 2007 / Accepted: June 2, 2008 / Published online: July 30, 2008

\begin{abstract}
The longitudinal modulus of elasticity of common yew is astonishingly low in light of its high raw density. At least this was found for specimens examined at the solid wood level and at the tissue level. However, to reveal if this low axial stiffness is also present at the cellular level, tensile tests were performed on individual yew fibers and on spruce fibers for reference. The results revealed a low stiffness and a high strain to fracture for yew when compared with spruce. This compliant behavior was ascribed to a relatively high microfibril angle of yew measured by X-ray scattering. It can be concluded that the high compliance of yew observed at higher hierarchical levels is obviously controlled by a structural feature present at the cell wall level. In future studies, the biomechanical function of this compliant behavior for the living yew tree would be of particular interest.
\end{abstract}

Key words Single fibers $\cdot$ Microfibril angle $\cdot$ Modulus of elasticity · Spruce (Picea abies) · Yew (Taxus baccata)

\section{Introduction}

With respect to its superior raw density $\left(620-720 \mathrm{~kg} \mathrm{~m}^{-3}\right.$ at $11 \%-12 \%$ equilibrium moisture content), yew wood stands out from other European gymnosperms. Its longitudinal stiffness, however, is astonishingly low. Most literature references report a longitudinal modulus of elasticity (MOE) between 6.2 and $12 \mathrm{GPa}^{1-3}$ This remarkable combination makes yew wood an interesting case study with regard to its structure-property relationship.

In two previous studies carried out at $20^{\circ} \mathrm{C}$ and $65 \%$ relative humidity $(\mathrm{RH})$, we analyzed the axial stiffness of

D. Keunecke $(\bowtie) \cdot$ P. Niemz

Wood Physics Group, Institute for Building Materials, ETH Zurich,

Schafmattstrasse 6, 8093 Zurich, Switzerland

Tel. +41-44-632-3232; Fax +41-44-632-1174

e-mail: danielk@ethz.ch

M. Eder · I. Burgert

Department of Biomaterials, Max Planck Institute of Colloids and Interfaces, Potsdam, Germany adult yew and spruce heartwood (as a reference) at two levels. First, at the solid-wood level, ${ }^{4} \mathrm{MOE}$ was determined in three-point bending tests according to the German standard DIN 52186 using a universal testing machine (Zwick Z100) and specimens as shown in Fig. 1. Second, at the tissue level, ${ }^{5}$ "dog bone" shaped slices (Fig. 1) cut from the radial plane of small wood cuboids were loaded in tension. The load cell of the micro stage detected the applied forces while strain was measured by video extensometry. The calculation of MOE was based on the sample cross sections measured on scanning electron microscopy images.

Both studies revealed a lower MOE for yew than for spruce and thus confirmed the above-mentioned literature references. The relatively compliant behavior of yew was ascribed to large microfibril angles (MFA) documented by X-ray diffraction ${ }^{4}$ and the pit aperture method. ${ }^{5}$

This conclusion implies that the elastic behavior of yew must also be present at an even lower hierarchical level, namely the fiber level. However, to clearly distinguish between mechanical performance arising from cell-cell interactions or cell wall properties, micromechanical tests have to be performed on individual fibers. Consequently, the goal of this current study was to compare individual yew and spruce fibers with regard to their longitudinal stiffness and further longitudinal mechanical properties. In addition, the MFA of the yew and spruce tissues used for fiber isolation was measured by small-angle X-ray scattering.

\section{Materials and methods}

Microtensile tests were performed on transition wood fibers (fibers from the zone between earlywood and latewood) of common yew (Taxus baccata L.) and Norway spruce (Picea abies [L.] Karst.). They were mechanically isolated from tangential tissue slices (as described by Burgert et al. ${ }^{6}$ ) taken at breast height from the outer heartwood region of trees grown close to Zurich, Switzerland. The approximate 


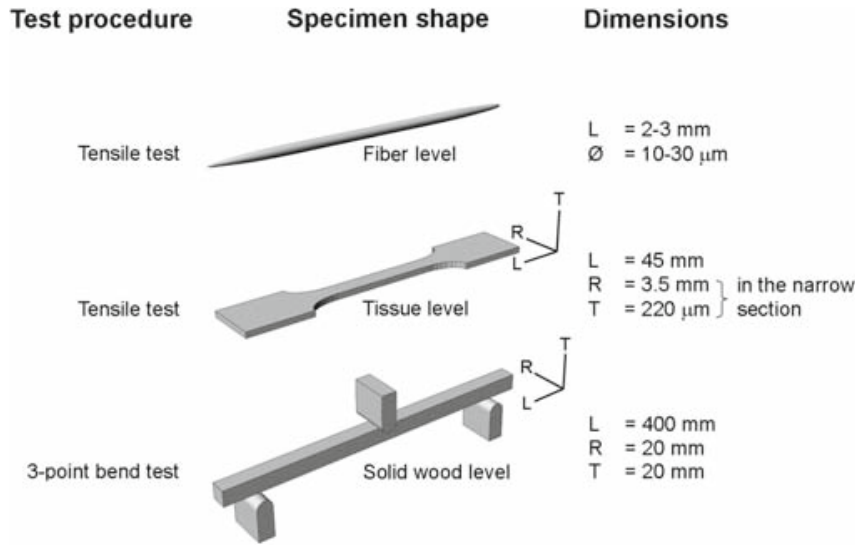

Fig. 1. Geometry of specimens tested at the fiber level (this study) the tissue level (Keunecke and Niemz ${ }^{5}$ ), and the solid-wood level (Keunecke et $\mathrm{al}^{4}{ }^{4}$ ) to determine the longitudinal modulus of elasticity
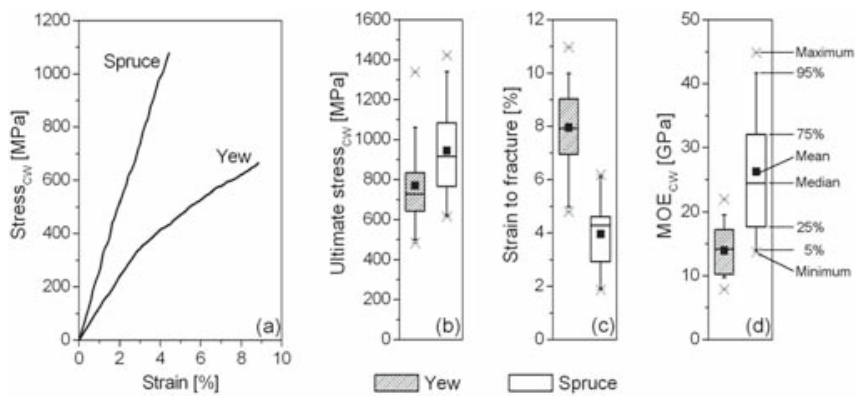

Fig. 2. a Representative stress $\mathrm{Cw}_{\mathrm{Cw}}$-strain curves of one yew and one spruce fiber subjected to longitudinal tension. Spruce shows roughly linear-elastic response while yew is characterized by biphasic behavior. Statistical spread of $\mathbf{b}$ ultimate stress $\mathrm{CW}_{\mathrm{CW}}$, c strain to fracture, and $\mathbf{d}$ $\mathrm{MOE}_{\mathrm{CW}}$ determined in 18 yew and 21 spruce experiments. MOE, modulus of elasticity; $\mathrm{CW}$, values based on the cell wall cross-sectional area. Microfibril angles measured on the tissue slices used for fiber isolation were $15^{\circ}-20^{\circ}$ for yew and $0^{\circ}-5^{\circ}$ for spruce

The mean ultimate tensile stress $\mathrm{CW}_{\mathrm{CW}}(\mathrm{CW}$ denotes calculation based on the cell wall cross section) was about $20 \%$ lower for yew than for spruce fibers (769 and $945 \mathrm{MPa}$ respectively; Fig. 2b). The mean strain to fracture was twice as high for yew as for spruce $(8.0 \%$ and $4.0 \%$ respectively; Fig. 2c). By contrast, the mean $\mathrm{MOE}_{\mathrm{Cw}}$ of yew fibers was approximately half as high as for spruce fibers (13.9 and 26.2 GPa respectively; Fig. 2d).

Supplementary structural examination revealed that the MFA of the S2 (by far the thickest cell wall layer) was clearly larger for yew than for spruce $\left(15^{\circ}-20^{\circ}\right.$ and $0^{\circ}-5^{\circ}$ respectively). This distinctive feature of yew fibers has already been found in previous studies. ${ }^{4,5}$ The observed differences between yew and spruce fibers in terms of their mechanical response can be largely attributed to the respective MFA: a higher MFA results in both a lower MOE and a higher extensibility in the longitudinal direction. ${ }^{9}$

Furthermore, a biphasic stress-strain curve, as found for yew fibers, is a common phenomenon among plant tissues with high microfibril angles in the S2 layer. ${ }^{10-13}$ It indicates an extraordinary longitudinal toughness of yew fibers because plastic deformation considerably contributes to their high strain to fracture. The larger MFA of yew fibers might also cause their slightly lower ultimate tensile stress. Because tensile forces are mainly carried by cellulose fibrils, different percentages of cellulose for yew and spruce are conceivable as well. However, this was not measured within this study.

The results show a typical characteristic of hierarchically organized materials: a feature of the material's ultra structure can have a strong impact on the mechanical behavior of clearly higher hierarchical levels. Previous studies on tissue and solid wood specimens ${ }^{4,5}$ revealed relations between the MOE of yew and spruce to be similar to those found in this present study. The comparison shown in Table 1 indicates that the lower stiffness of yew is present at all investigated hierarchical levels. Remarkably, the $\mathrm{MOE}_{\mathrm{CW}}$ did not vary between the hierarchical levels in both species. 
Table 1. Mean axial stiffness of yew and spruce determined at the fiber level and at higher hierarchical levels at $20^{\circ} \mathrm{C}$ and $65 \%$ relative humidity

\begin{tabular}{llll}
\hline Species & Hierarchical level & MOE $_{\mathrm{CW}}(\mathrm{GPa})$ & $\operatorname{MOE}_{\mathrm{CSA}}(\mathrm{GPa})$ \\
\hline Yew & Fiber $^{\mathrm{a}}$ & $13.9(36.6 \%)$ & \multicolumn{1}{c}{} \\
& Tissue $^{\mathrm{b}}$ & $15.6(26.9 \%)$ & $7.0(23.9 \%)$ \\
\multirow{3}{*}{ Spruce } & Solid wood $^{\mathrm{b}}$ & $14.3(20.3 \%)$ & $9.7(17.0 \%)$ \\
& Fiber $^{\mathrm{a}}$ & $26.2(28.3 \%)$ & - \\
& Tissue $^{\mathrm{b}}$ & $29.4(18.6 \%)$ & $9.9(21.5 \%)$ \\
& Solid wood $^{\mathrm{b}}$ & $28.1(8.4 \%)$ & $12.1(12.2 \%)$ \\
\hline
\end{tabular}

Data presented are mean values. Fiber level: yew, $n=18$; spruce, $n=21$. Tissue level: yew, $n=41$; spruce, $n=40$. Solid-wood level: yew, $n=60$; spruce, $n=60$. The data for the tissue level are mean values for two specimen series per species. Figures in parentheses are coefficients of variation

$\mathrm{MOE}_{\mathrm{CW}}$, modulus of elasticity based on the cell wall area; $\mathrm{MOE}_{\mathrm{CSA}}$, modulus of elasticity based on the total cross-sectional area including lumens

${ }^{\mathrm{a}}$ This study

${ }^{\mathrm{b}}$ Keunecke et al., ${ }^{4}$ Keunecke and Niemz

\section{Conclusions}

With this study, we showed that the high longitudinal compliance (i.e., the low MOE and simultaneously high strain to fracture) of yew wood observed in two preceding studies at higher hierarchical levels is also present at the fiber level. This behavior was ascribed to the relatively large MFA. Thus, in view of its high density, yew is a prime example to demonstrate that the axial stiffness of the hierarchically organized biomaterial wood is obviously controlled by a feature that is present at the cellular level.

In view of its anatomic and mechanical properties, yew wood takes an intermediate position between typical normal and compression wood. Therefore, its biomechanical function in the straight trunk of the living tree would be of particular interest for future studies.
Acknowledgments This work was supported by the European Cooperation in the field of Scientific and Technical Research (COST Action E35) for a short-term scientific mission (STSM) stay by D. Keunecke at the Biomaterials Department at the Max Planck Institute of Colloids and Interfaces (Potsdam, Germany). We are grateful to Oskar Paris, Max Planck Institute of Colloids and Interfaces, for determining microfibril angles.

\section{References}

1. Sekhar AC, Sharma RS (1959) A note on mechanical properties of Taxus baccata. Indian Forest 85:324-326

2. Jakubczyk B (1966) Technical properties of the yew wood from the preserve Wierzchlas. Sylwan 10:79-86

3. Wagenfuhr R (2000) Holzatlas. Fachbuchverlag Leipzig, Munich, p 707

4. Keunecke D, Marki C, Niemz P (2007) Structural and mechanical properties of yew wood. Wood Res 52:23-38

5. Keunecke D, Niemz P (2008) Axial stiffness and selected structural properties of yew and spruce microtensile specimens. Wood Res 53:1-14

6. Burgert I, Keckes J, Fruhmann K, Fratzl P, Tschegg SE (2002) A comparison of two techniques for wood fibre isolation evaluation by tensile tests on single fibres with different microfibril angle. Plant Biol 4:9-12

7. Burgert I, Fruhmann K, Keckes J, Fratzl P, Stanzl-Tschegg SE (2003) Microtensile testing of wood fibers combined with video extensometry for efficient strain detection. Holzforschung 57: 661-664

8. Burgert I, Eder M, Fruhmann K, Keckes J, Fratzl P, Stanzl-Tschegg S (2005) Properties of chemically and mechanically isolated fibres of spruce (Picea abies [L.] Karst.). Part 3: mechanical characterisation. Holzforschung 59:354-357

9. Reiterer A, Lichtenegger H, Tschegg S, Fratzl P (1999) Experimental evidence for a mechanical function of the cellulose microfibril angle in wood cell walls. Philos Mag A 79:2173-2184

10. Bodig J, Jayne BA (1993) Mechanics of wood and wood composites. Krieger, Malabar, FL, p 712

11. Navi P, Rastogi PK, Gresse V, Tolou A (1995) Micromechanics of wood subjected to axial tension. Wood Sci Technol 29:411-429

12. Kohler L, Spatz HC (2002) Micromechanics of plant tissues beyond the linear-elastic range. Planta 215:33-40

13. Keckes J, Burgert I, Fruhmann K, Muller M, Kolln K, Hamilton M, Burghammer M, Roth SV, Stanzl-Tschegg SE, Fratzl P (2003) Cell-wall recovery after irreversible deformation of wood. Nat Mater 2:810-814 